\title{
Circo que Foge com o Sonho: planos de fuga e estratégias pedagógicas para sonhar
}

\author{
Bianca Scliar ${ }^{1}$ \\ Bruna Ferracioli ${ }^{2}$
}

Recebido em: 12/09/2018

Aprovado em: 20/11/2019

DOI: $10.5965 / 2358092521222019030$

\footnotetext{
${ }^{1}$ Doutora em Artes e Filosofia pela Concordia University (Montreal/Canadá). Professora do Departamento de Artes Cênicas da Un'iversidade do Estado de Santa Catarina (UDESC). E-mail: bibimove@gmail.com

${ }^{2}$ Graduanda em Licencitura em Teatro na Universidade do Estado de Santa Catarina (UDESC). Diretora de Teatro e ensaísta. E-mail: brunaraferracioli@gmail.com
} 


\section{RESUMO}

Este trabalho apresenta resultados de um projeto de ensino de teatro executado a partir de noções expandidas de comunidade e resultante de estudos sobre a pedagogia radical. Convidamos à reflexão sobre oportunidades disponíveis para rasgar limites metodológicos no contexto da pedagogia da cena, sejam eles referentes a subcategorias da performance teatral ou do que pressupomos ser uma comunidade, ou mesmo àquilo o que definimos como processos de aprendizagem e seus objetivos determinados antecipadamente. No contexto de um estágio em comunidade esta análise se instaura a partir da noção de planos de fuga, dos filósofos Guattari e Deleuze, e alcança questionamentos sobre o lugar de ensino, reflete sobre uma pedagogia do sonho e indaga sobre as implicações de constituir comunidades efêmeras a partir do acontecimento de uma aula de teatro.

Palavras-chave: Ensino de Teatro. Escultura Social. Arte Participativa. Pedagogias na rua.

\section{ABSTRACT}

This work presents the result of a teaching practice in theater, executed from expanded notions of community and as a result of our studies in radical pedagogies. We invite to a reflection about available opportunities to restore methodological limits in the context of performance pedagogies, either from the subcategory of theater performance or from what is understood as a community practice in theater, furthermore, to reflect upon learning processes and the predetermined goals in theater. In the context of a community-theater practice, this analysis is installed in the notions of fugitive planning, from Deleuze and Guattari and aims to reach some key questions about where is the place for teaching, echoing a pedagogy 
of dreams and inquiring on the implications on constituting ephemeral communities of events at a theater class.

Keywords: Theater Teaching. Social Sculpture. Participative Art. Street Pedagogies.

\section{A COMPOSIÇÃO DO SONHAR}

Quando a mente sonha o corpo fala sem usar a cabeça.

(A. Alvarez, 1996).

O que você sonhou essa noite? Você tem sonhado ultimamente? Conseguiria contar algum dos seus sonhos mais recentes? Estas perguntas foram feitas para os participantes do projeto sobre o qual este texto disserta. A experiência, desenvolvida ao longo de 2018 com um grupo misto e heterogêneo nas ruas e em alguns circuitos fechados da cidade de Florianópolis ${ }^{3}$, num primeiro momento recebeu o nome "O sonho de fugir com o circo" e posteriormente foi chamada de "Circo que foge com o sonho".

As questões postas à turma de participantes carregam propositalmente uma abordagem especulativa sobre a capacidade de sonhar, seja em vigília ou em sono. Aqui explicitamos como este projeto não se restringe à noção de sonho enquanto construção imagética simbólica, mas estende-se a uma dimensão incorporal, que requer uma abordagem que margeia algumas metodologias e práticas pedagógicas em teatro. Notadamente tomamos os sonhos não como uma metáfora ou elucubrações simbólicas, passíveis de serem arranjadas por uma lucidez vigilante, que Ihes atribui causas, efeitos e significados. Interessamo-nos por indagar como pode a habilidade em sonhar, em vivenciar o indescritível, formular estados de estudo e de aprendizagem através e com o ensino do teatro. Ao longo deste texto

30 projeto foi realizado como parte das disciplinas de Estágio na Comunidade I e II, do Curso de Licenciatura em Teatro da UDESC, pelos acadêmicos Bruna Ferracioli e Vinicius Pereira, orientado pela professora Bianca Scliar, com as disciplinas ministradas por Flávio Desgranges e Rosemeire da Silva. 
procuraremos compartir alguns pontos sobre a complexidade de engajar o espaço no estudo de corporealidades cênicas, simultaneamente a um processo de improvisação e composição através das imagéticas circences, um estudo que nos permitiu lançar luz sobre a importância da cidade e dos sonhos de fuga alimentados no estudo e prática teatral.

Colocar o pensamento em ação, essa seria a habilidade contida no verbo "sonhar" que rodeamos com as proposições pedagógicas do projeto. Erin Manning (2008) indica, através de seu minucioso trabalho sobre pedagogias e processos de criação, a dificuldade em transitar e propor procedimentos de pesquisa-criação. Através do trabalho da artista Amanda Baggs ${ }^{4}$, Manning destaca que o corpo e a relação com os objetos, com a arquitetura e seu entorno, podem sempre ser tomados como novidade, sonhados. Ela escreve:

Nenhum objeto é tomado simplesmente pelo que parece ser: cada objeto modula a ressonância da voz, movendo seu próprio movimento em conjunto com o ambiente em movimento. Em uma multiplicação suprasensorial de eventos e devir, observamos como a cena muda de um frenesi de papel trêmulo para um close estonteante de uma maçaneta redonda, com os dedos circulando, a própria imagem girando como se estivesse presa em seu próprio momento, o corpo de Amanda perdendo-se num livro, o rosto cheirando suas páginas, a textura do papel roçando sua pele, sentindo, balançando, cheirando, balançando, tocando. A cada encontro com o ambiente emergente, uma nova relação nasce. (MANNING, 2008, s/p, tradução nossa)

Essa premissa sugere um processo pedagógico que não pode antecipar ou definir o conteúdo ou forma de seus resultados. Entretanto, a inventividade desse planejamento deve poder contribuir para a "criação de nexos relacionais" (MANNING,

4 Amanda Baggs faz parte de uma jovem geração de artistas que são diagnosticados como autistas e que vem desafiando todos os tipos de diagnósticos e categorizações sobre expressividade e pensamento, através da produção de complexos trabalhos, da dança, vídeo-arte, poesia, etc. Para biografia, obras e links relacionados ao ativismo de Baggs, consultar http://abaggs.blogspot.com/ 
2008, s/p, tradução nossa), o que Manning descreve como sentir o mundo diante da incipiência a partir de um devir sensorial, um fazer que produz em si uma forma de pensamento. O movimento deste pensamento não pode, segundo a argumentação de Manning, restringir a complexidade de sua pré-articulação através de uma estrutura de expressão baseada em conteúdo e, ao resistir a esta simplificação, escapa por algo que Amanda Baggs sugere surgir nos contornos da linguagem, através de uma complexidade relacional. A artista explica:

Longe de ser sem propósito, a maneira como me movo é uma resposta contínua ao que está ao meu redor. Ironicamente, a maneira como me movo ao responder a tudo ao meu redor é descrita como 'estar em um mundo próprio', enquanto que se eu interagir com um conjunto muito mais limitado de respostas e reagir apenas a uma parte muito mais limitada do meu entorno as pessoas afirmam que estou 'me abrindo para uma verdadeira interação com o mundo'. (apud MANNING, 2008, s/p, tradução nossa).

Destacamos essa perspectiva para indicar, de antemão, o quanto nossa proposição pedagógica tencionou os discursos sobre uma prática de teatro na rua, terminologia que supõe a localização como mero ambiente para uma ação corpórea e exercício de subjetividades aplicadas à cena. Aqui tateamos uma provocativa formulação a respeito das interações entre corpo e espaço, expressividade e processos de aprendizagem, próximas às colocações levantadas por Baggs e Manning. Complementarmente enlaçamos nossa proposição pedagógica com a chamada teoria do afeto, delineada no livro Parables for the Virtual, Movement, Affect, Sensation (2008), por Brian Massumi. Em sua filosofia especulativa Massumi propõe a noção de um corpo que não pode ser definido por sua localização, mas por seus fluxos, sugerindo a superação da linearidade analítica entre corpo (aquilo o que é concreto) e o movimento.

Ao nos debruçarmos sobre o sonho enquanto capacidade criadora e exercício da pré-linguagem de liberdade, tornou-se necessário reconsiderar as noções apresentadas e tecidas pelos autores e autoras que indicamos neste texto, pois só assim 
pudemos experimentar pedagogias da cena e da coletividade cênica que sugerissem operadores processuais (termo cunhado também por Massumi e Manning) em uma economia de atenções centralizada nas relações compostas em movimento, a cada encontro.

Acolhemos o processo de aprendizagem e de estudo como uma transformação em si mesma, e não como um deslocamento rumo a um fim aquisitivo de uma habilidade previamente definida. Mesmo ao planejar e avaliar processos de estudo e aprendizagem, nossas práticas pedagógicas erguem-se sobre o hábito de avaliar deslocamentos e não a transformação em si mesma, alerta Massumi (2008) em alusão à máxima Bergsonia$n a^{5}$ de que o movimento está subordinado às posições assumidas, começos e fins, deixando de lado a valoração das transformações qualitativas que ocorrem.

Em um programa de ensino enquanto o corpo concreto é mediado através de proposições de jogos teatrais suas qualidades e abstrações vividas, ou seja, os aspectos imateriais dos sonhos, também são considerados em nossas propostas e nas situações de ensino-aprendizagem. Seria possível uma estrutura pedagógica que preservasse o "poder do falso", a fabulação e a capacidade de sonhar, partilhados no encontro que chamamos "aulas de teatro"? Quais parâmetros poderiam ser desprezados para que este campo da fabulação prevalecesse nas iterações dos exercícios teatrais propostos? Nosso parâmetro para orientar e reorientar as proposições pedagógicas pretendia circundar essas perguntas e honrar a premissa destacada por Manning de "sentir o impulso". Ela descreve:

Pense no valor como um mecanismo para a extrusão das qualidades da força ao longo do processo de força que toma forma. [...] Objetos relacionais de Lygia Clark criam mundos: é assim que seu valor é sentido. Esses objetos - sacos de plástico cheios de ar, redes com pedras - têm pouco valor artístico por si mesmos. 0

50 filósofo Henri Bergson discorre largamente ao longo de suas obras Matéria e Memória (1896) e Evolução Criadora (1907) sobre o problema do movimento e do fluxo como instâncias primeiras para a atribuição de valores da matéria. 
valor dos objetos relacionais de Lygia Clark não se expressa em sua capacidade de se sustentarem sozinhos. Seu valor é sentido nas qualidades emergentes ao acoplarem-se com corpos-em-relação. Seu valor está em como as forças do potencial se expressam através do movimento relacional em direção ao mundo. Seu valor não pode ser separado das restrições de ativação do processo. (MANNING, 2008, s.p, tradução nossa).

E, assim, lançamo-nos a entrelaçar circo, sonho, fugas, numa proposta pedagógica desterrada, que sempre estava aberta à participação contínua e descontínua, passeando por praças da cidade, deslocando métodos em saltos através das qualidades, demandas, vontades, curiosidades e sonhos que iam surgindo com os encontros, levando-nos a desenhar desvios e estratégias ousadas ao longo do ano em que a proposta foi realizada. As acepções dos estudos culturais propostas por Massumi, Manning e também por Harney e Motten (2013) sugerem uma compreensão particular do campo de presença e significações compositivas que tensionam a máxima aferida com frequência de que "algo deve ser feito para romper o cotidiano", aquele lugar onde "nada acontece" (MASSUMI, 2002, p. 01). Sempre já há o sonho, transitando nos espaços da cidade, assim, ao invés de pensarmos sob a perspectiva de um ensino que medeia e que, por definição, supõe que o corpo é essencialmente discursivo, a abordagem especulativa nos encaminhou para a composição de uma ecologia de práticas, estruturando o projeto pedagógico a partir do que Fred Moten e Stefano Harney (2013) indicaram como planos de fuga.

Existe nos planos de fuga uma movimentação do próprio acontecimento pedagógico, em que a organização que emerge no encontro exerce um papel fundamental sobre o que de fato está em jogo nos processos de aprendizagem, o que importa e quais acontecimentos são valorizados. Planejar é criar maneiras de alinhar-se ao trabalho já em andamento, onde aqueles que planejam ainda fazem parte do plano. Harney e Motten escrevem: "E o plano é inventar os meios para um experimento comum, lançado de qualquer cozinha, qualquer varanda dos fundos, qualquer porão, qualquer salão, qualquer banco de par- 
que, qualquer festa improvisada, todas as noites" (2013, p. 7475). Não se trata de atividades, pescar ou dançar ou ensinar ou amar, mas o incessante experimento com a presença de formas de vida, os sonhos que tornam tais atividades possíveis, complementam os autores.

Chama-nos a atenção o fato de que, durante o processo pedagógico, nos momentos em que tencionamos as questões provocadoras a respeito do sonho, o silêncio era predominante. Criamos algumas hipóteses: ou as pessoas estão com dificuldade para lembrarem-se de seus sonhos, ou têm vergonha do que estão sonhando, ou simplesmente pararam de sonhar, ou ainda, teríamos alcançado um tecido intangível, da fabulação, que, ao romper-se em linguagem, afasta-se de sua própria composição, não se coincide com si mesmo.

Da intenção de falar sobre o sonho como material pedagógico e artístico, para além do sonho como inspiração metafórica para a criação ou desenvolvimento de uma obra de arte, consideramos alguns componentes fundamentais da experiência onírica, a partir das ponderações elaboradas pelo filósofo Henri Bergson (1901). Em seus escritos sobre o sonho, o autor afirma que "O eu que sonha é um eu distraído, que se distende. As lembranças que se harmonizam melhor com ele são as lembranças de distração, as que não trazem a marca do esforço" ${ }^{\prime 6}$. Bergson (1901, p. 109) alega que "em geral o sonho não cria nada", pois se trata "apenas de uma ressurreição do passado". Mas sabemos que essa "ressurreição" não ocorre tal quais as experiências resgatadas. O filósofo explica que o sonho consiste em "uma reunião desprovida de sentido", de diversas lembranças abolidas, sensações e detalhes despercebidos. Ao traçarmos um paralelo entre esse pensamento de Bergson acerca do sonho e o conceito de planos de fuga aplicado ao campo artístico, é possível notar que há uma aproximação da ideia de "reunião" anunciada pelo autor e a técnica de criação artística de colagem,

6 Essas palavras foram proferidas em uma Conferência realizada no Instituto Geral Psicológico, intitulada "O mecanismo, a rapidez, a instabilidade e o retorno das lembranças fugidias dos sonhos". 
que pode ser definida como uma compilação de um conjunto de imagens resgatadas.

Ao mesmo tempo em que, no entanto, percebe-se essa correlação entre sonho, colagem, criação e arte, vê-se também a alegação de Bergson de que "o sonho não cria nada" (1901, p. 109). Esta ponderação nos levou a refletir sobre o processo pedagógico que tem como objetivo uma espécie de composição cênica ou encenação. Se o sonho é o resultado de uma capacidade de fabulação e rearranjo de uma parcela da experiência vivida, não é possível um processo criativo que não esteja amparado em aspectos da realidade vivida e partilhada, que o sonho cria e nos permite reparar.

No livro A Noite, o escritor Alfred Alvarez constrói uma micro-ontologia do sonho e propõe explicar a estrutura de um sonho para sugerir o consiste o sonhar:

Sonhar é pensar sem o intelecto, pensar em termos corpóreos. E porque sonhar é puramente uma experiência mental que ocorre, sobretudo durante a fase REM do sono, quando o corpo está inativo - os músculos virtualmente paralisados, as reações motoras inibidas -, faz sentido, de modo paradoxal e compensatório, que os sonhos nos falem numa linguagem física, concreta, que os pensamentos e sentimentos sejam expressos como coisas e ações, em gestos e imagens, e não de maneira abstrata em palavras. (ALVAREZ, 1996, p. 163).

A reflexão nos convida a rever o que compreendemos como um processo pedagógico em teatro, um processo de ensino no campo da criação. Tentar entender a não lógica que rege o funcionamento de nosso organismo quando estamos dormindo, pode nos ajudar a entender também que, quando acordados, vivemos sob um regime de lógicas lineares, que desprezam os planos de fuga. Podemos citar uma lógica naturalizada na contemporaneidade: a nossa relação com o tempo, com os seus instrumentos e consequentemente, com a ideia de falta de tempo. Se sonhar requer pensar em termos corpóreos, o ato criador, ou, a pedagogia de um processo de criação, requer 
que pensemos nos fundamentos do próprio processo de ensino-aprendizagem.

Nesse sentido, um estudo a respeito dos sonhos e do ato de sonhar parece bastante intrigante, pois, ao nos depararmos com outra forma de sentir o mundo, que muitas vezes se constitui de elementos absurdos e colagens pouco refinadas de sentido, nos deparamos também com a parte igualmente intangível que se emaranha na realidade desperta. Portanto, utilizar-se da composição do sonhar para construção de um projeto artístico-pedagógico preocupa-se em refinar nossas percepções de mundo e (re)inventar novas maneiras estar acordado.

\section{DESENHAR PROPOSIÇÕES}

Os primeiros traços do projeto de ensino surgiram a partir do desejo em (re)pensar os espaços de composição pedagógica que uma Universidade de Artes pode oferecer. Também é importante ressaltar que a realização dessa proposta pedagógica como atividade institucional, no âmbito acadêmico, só foi possível devido ao nosso incubamento ao programa de extensão LabEl (Laboratório de Ensaios e Imprevistos), coordenado pela professora Bianca Scliar ${ }^{7}$. Neste projeto entendeu-se como comunidade o público alcançado pelo programa de extensão. Isso possibilitou o estabelecimento de outra qualidade para o que se compreende como comunidade externa e como Extensão, uma vez que o surgimento de um grupo limiar, que se interessava pelas atividades desenvolvidas no âmbito acadêmico, mas que não está direta e formalmente associado à Instituição extrapolava o entendimento óbvio de uma inserção em uma comunidade já definida.

Inicialmente "O Sonho de fugir com o circo" consistia em aulas públicas de teatro na rua, inspiradas em poéticas circen-

7 A Extensão Universitária é uma ação de desenvolvimento social da Universidade que possibilita a integração entre o espaço público da academia e sua produção de conhecimento, com a comunidade externa. Isso promove a participação ativa da população e viabiliza o acesso aos benefícios que uma Universidade oferece. 
ses $^{8}$. Nessa fase as aulas aconteciam em espaços tais como praças, calçadas e parques, e tinham caráter itinerante, ou seja, a cada reunião era estabelecido um novo local para o próximo encontro. Seguindo esse arranjo, a primeira fase foi finalizada com dez encontros pela cidade de Florianópolis, nas quais foram desenvolvidas atividades como contação de histórias, danças, acrobacias, mágicas e, inclusive, um pequeno festival de rua.

Foi possível identificar nesta primeira etapa, uma atmosfera ou estética mais relacionada ao dia, ensolarada, denotada na tonalidade predominante no cartaz de divulgação do projeto era uma cor quente (vide FIGURA 1). No entanto, essa sensação só pôde ser percebida quando se iniciou a segunda fase dessa experiência, nomeada "Circo que foge com o sonho".

8 Por "poéticas circenses" entendemos e fazemos respeitosa menção ao que pode ser considerada a "arte de rua" ou "arte itinerante": A arte do artista autônomo, que compõe o (extra)ordinário, dialogando com a sua realidade cotidiana e enfrentando todo e qualquer desafio que a rua pode lhe proporcionar. 


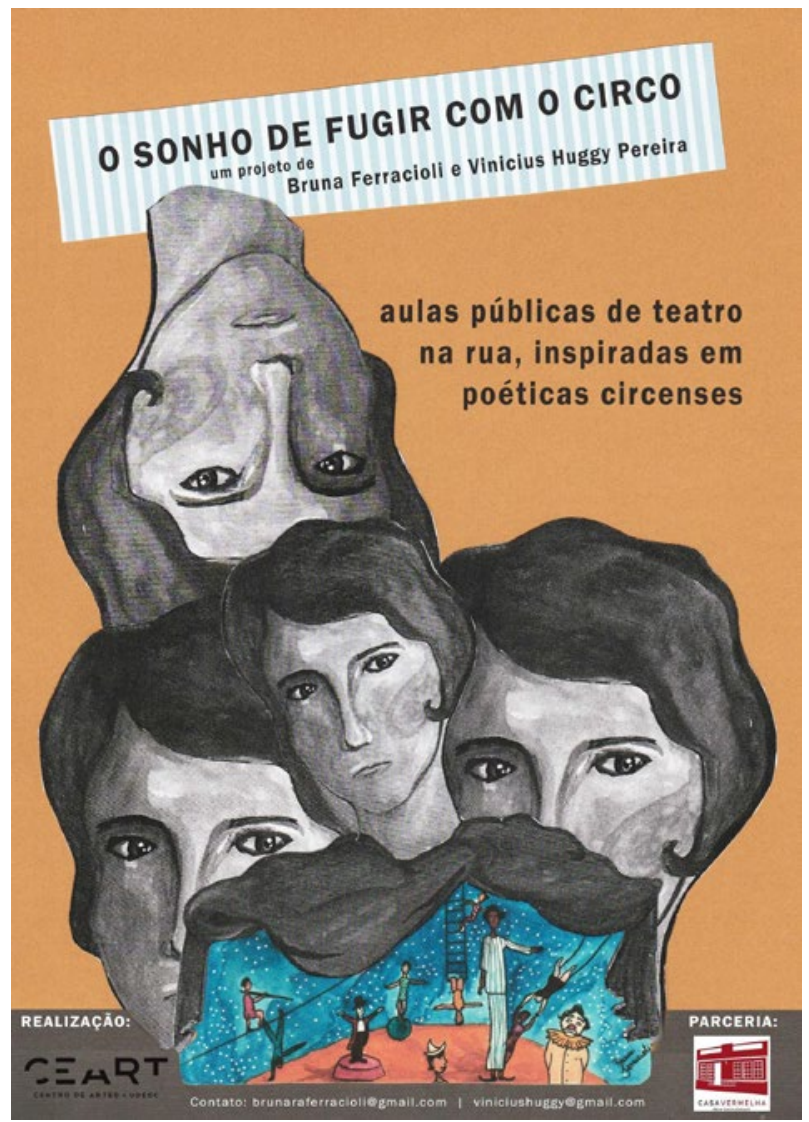

Figura 1: Cartaz utilizado durante o primeiro semestre de 2018

Fonte: acervo das autoras.

A escolha por modificar o título do projeto, brincando com suas possibilidades e reversibilidades, é justificada principalmente pela vontade dos idealizadores de (re)significar algumas decisões tomadas anteriormente. Também surgiu, nesse segundo momento, o interesse em refletir mais sobre a questão dos sonhos e consequentemente da noite. A mistura dos tons de violeta e azul tomaram a vez do amarelo quase laranja, que tin- 
gia o nosso cartaz na fase anterior e definitivamente a atmosfera da noite foi instaurada (vide FIGURA 2).

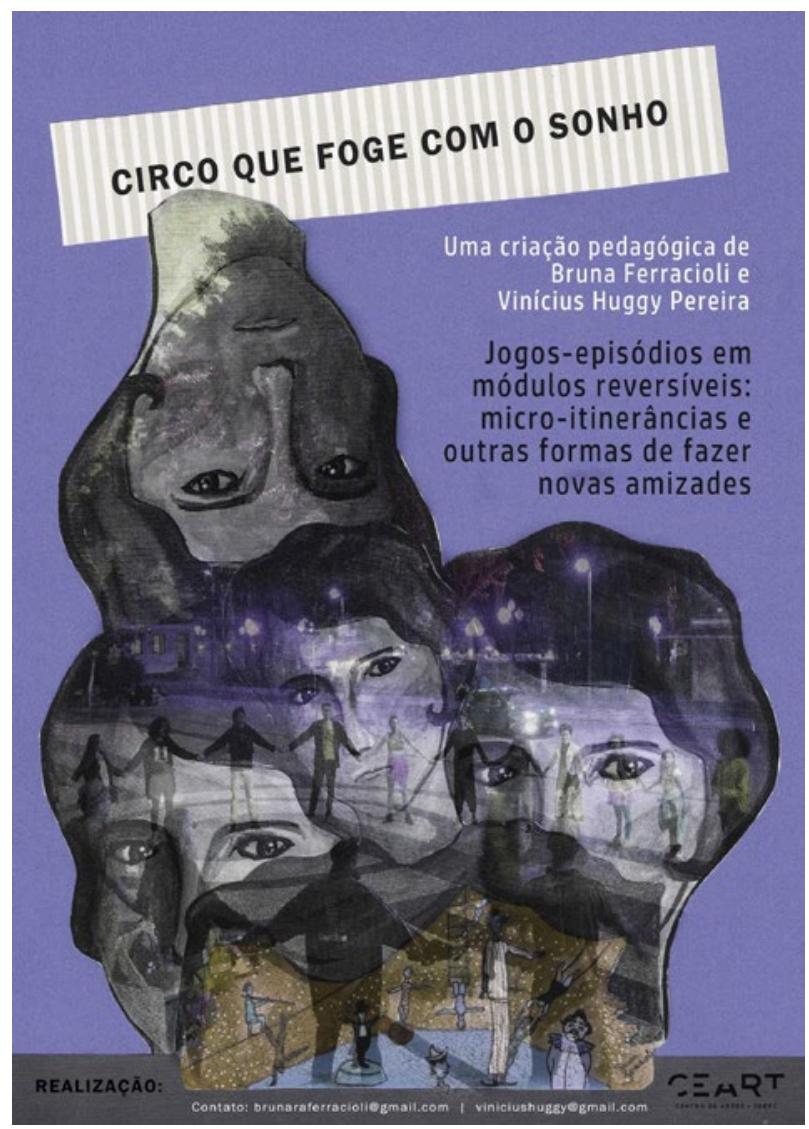

Figura 2: Cartaz utilizado durante o segundo semestre de 2018

Fonte: acervo das autoras.

O "Circo que foge com o sonho" foi uma experiência pedagógica em que nos encorajamos a extrapolar limites que resistiam em configurar-se nas estruturas de aula que até então conduzíamos. Apesar de ter sido desenvolvida em espaços fechados 
e salas de prática cênica e não mais nas ruas, abdicamos de um aspecto que é tido como o pressuposto em um processo de ensino-aprendizagem: o compromisso com a frequência no tempo.

Os encontros, que eram semanais passaram a ser irregulares e com uma noção de duração mais fluida. Isso ocorreu porque nesse momento o projeto se configurou como uma reunião de processos metodológicos (re)inventados. Dessa forma, este circo de metodologias em fuga se dispôs a visitar grupos de teatro já existentes que se disponibilizassem para uma intervenção artístico-pedagógica, embasada no desenvolvimento de práticas corporais e com o intuito de refletir sobre ensino de Arte e de Teatro. A proposta, portanto recebeu um novo subtítulo - “jogos-episódios em módulos reversíveis: micro-itinerâncias e outras formas de fazer novas amizades". Aqui estávamos interessadas em experimentar a invenção de uma metodologia para o ensino de teatro, que se desprendesse dos elementos que nós já sabíamos que funcionavam, por isso a transgressão da frequência temporal e a utilização de um lugar, não mais fixo para dar aula.

Foram feitas seis intervenções, em três espaços distintos, com grupos que já compartilhavam certa afinidade com as artes do corpo. Nessa fase foi elaborado um plano único de aula, aplicado várias vezes em contextos sociais e etários distintos. Assim procuramos, na soma das práticas, investigar como operam as técnicas e proposições do professor em grupos com trajetórias diferentes. Qual técnica afinal estava em jogo em nossas aulas? Qual o tipo de proposições para a improvisação que pode o professor oferecer, sem desviar dos contextos e vontades, de modo a abraçar as qualidades de execução e inventividade de cada situação onde o "plano" foi aplicado? A provocação de utilizar o mesmo plano de aula foi aqui uma estratégia para circundar essas perguntas. No contexto do estágio, tivemos a oportunidade de conversar com muitos docentes que alegavam não conseguir desenvolver simultaneamente aulas distintas e por isso aplicavam os mesmo jogos de encenação em várias turmas. Dentre os argumentos que escutamos, muitos desses professores explicavam que na maioria das instituições de ensino era desconsiderado o tempo de preparação da aula, o que desfavorecia 
o desenvolvimentos de projetos que contemplassem individualmente cada turma, pensando suas heterogeneidades.

A partir desse quadro, muito comum no contexto do ensino formal, ocorreu-nos pensar um plano de aula que pudesse funcionar em contextos diversos. Aproveitamos da nossa situação de "dupla docência", para ministrar uma aula que englobasse diversos acontecimentos simultâneos. Isso nos permitiu traçar um caminho de via dupla no período de estudo. Ao mesmo tempo em que um dos grupos de alunos fazia uma atividade, esse mesmo grupo aprendia e aumentava seu repertório enquanto assistia o grupo ao lado, que desempenhava outro exercício. Para intensificar isso, foram criadas algumas estratégias para inserir pausas durante o exercício, que enunciassem a vontade de um grupo de assistir o outro. Esses jogos não apenas desenvolviam a capacidade criativa das participantes, bem como inspiravam a investigação da emancipação e da autonomia dos alunos participantes da aula.

Trazer a temática dos sonhos como conteúdo, também deu suporte para que os estudantes se identificassem mais com as propostas do processo. Por ser o sonho um material tão maleável e de rápida identificação, era possível abordar temas transversais, dentro de uma mesma estrutura de aula. Isso nos permitiu compor aulas que atendessem às urgências de diferentes grupos, partindo de um mesmo plano de aula, ou seja, lançar-nos para planos de fuga, em que cada aula nos levava para discussões paralelas à proposição e nos fornecia material para improvisar dentro de um repertório inventado pela turma.

9 As oficinas foram ministradas simultaneamente por dois alunos da graduação, Vinicius Pereira e Bruna Ferraccioli. 


\section{A METODOLOGIA DE BRINCADEIRA, UM SO- NHO DE AULA}

E para nós o possível se tornou mais necessário que o real porque o real, embora nos mantivesse seguros e assegurados, havia começado a nos asfixiar. (Jorge Larrosa, 2015)

O trabalho, desde o início, carregou em seu cerne o desafio da experimentação. Na fase "O sonho de fugir com o circo", era também parte da proposta desapegar-se de algumas certezas que já tinham sido inventadas sobre o ensino de Teatro com o intuito de promover experiências artísticas e coletivas. A primeira certeza renunciada foi em relação ao espaço, por isso a escolha de ir para a rua e de ser itinerante. Diversas questões atravessaram essas escolhas: o desejo de ocupar outros espaços com arte, o sonho de espetacularizar a rua com práticas cênicas, o reconhecimento de como a prática em teatro pode recobrar a capacidade de sonhar nos mais distintos contextos sociais, a vontade de intervir em outros espaços de ensino, para propor novas práticas e aprender com o que cada lugar e situação propõem. A proposta alinha-se com o que vem sido chamado de a poética das Pedagogias Radicais definida por Bianca Scliar Mancini assim:

Uma pedagogia radical associa-se ao conceito de performance para ocupar-se com uma afinidade conjuntural, com a capacidade de colaborar com o que é apresentado nas condições para o evento. Sob esta perspectiva não há técnicas singulares capazes de ensinar artistas a tornar seu trabalho funcional ou mais expressivo, apenas a possibilidade de promover um engajamento com a investigação de fronteiras. É este movimento partilhado com aquele que estuda, que experimenta, que pode eventualmente ensinar sobre o potencial de coletividade, fricção e ativação poética e política em uma escala que poderia passar despercebida na esfera da vida cotidiana. Nas fronteiras alcança-se algo distintivo para as pedagogias radicais, o instante em que o processo de aprender e ensinar reverte o equilíbrio 
que tornou relações cotidianas (entre saberes e sujeitos) praticamente invisíveis e seu potencial de transformação congelado. (MANCINI, 2016, p.15).

Complementar a esta ideia de que uma pedagogia radical elabora condições e não se ocupa em ensinar diretividades para uma maior funcionalidade ou expressividade no processo de criação artística, Larossa acrescenta:

Agora que já não podemos crer no que acreditávamos nem dizer que dizíamos, agora que nossos saberes não se sustentam sobre a realidade nem nossas palavras sobre a verdade, talvez seja a hora de aprender um novo tipo de honestidade que se exige para habitar com a maior dignidade possível um mundo caracterizado pelo caráter plural da verdade, pelo caráter construído da realidade e pelo caráter poético e político da linguagem. (LARROSA, 2015, p. 164).

Destacamos esses recortes teóricos conceituais para propor uma formulação de uma pedagogia de fronteira, entre linguagens, entre situações, entre acomodações da própria linguagem que narra o processo de ensino e aprendizagem no teatro. Por isso denominamos esta proposta como uma metodologia de brincadeira, uma proposta pedagógica bastante inspirada em alguns processos utilizados para o ensino da palhaçaria. O desejo de se dispor da situação do brincar como proposição para ensinar, encontra em si um outro querer, o de (re)aproximar a pedagogia do riso e da ludicidade. Larrosa (2015) versa, em seu livro intitulado "Pedagogias Profanas", que a Pedagogia se ri pouco. Ainda acrescenta que "O riso destrói as certezas. E especialmente aquela certeza que constitui a consciência enclausurada: a certeza de si." (LARROSA, 2015, p. 181). A partir dessas provocações, a metodologia de brincadeira sugere um espaço de aprendizagem no qual rir faz parte da forma e do conteúdo.

A ativação de uma sensibilidade lúdica nas participantes e consequentemente uma nova forma de se relacionar com a realidade que está guardada em alguns jogos teatrais, mas aqui preferimos a brincadeira que guarda em si um plano de sonho não determinado. 
Ao nos comprometer com a noção de "metodologias em fuga", acolhemos a itinerância como mudança de lugares, mudança de destinos, mudança de planos (sonho- cotidiano, por exemplo). As metodologias em fuga correspondem ao conjunto de práticas pedagógicas selecionadas para serem aplicadas num contexto de itinerância, ou seja, com a intenção de propor aos participantes que acompanhem o deslocamento das aulas e se disponham a fugir com tais metodologias, não se trata de desvios aleatórios. Compreendemos a noção de metodologias em fuga pressupondo que as práticas pedagógicas escolhidas para compor o plano de aula precisavam encontrar em si mesmas o movimento e a capacidade de auto adaptação, de forma que fugissem de um possível congelamento e uma rígida sistematização- proposições que fogem de si mesmas?

Como já foi explicitado anteriormente, o primeiro e o segundo semestre do projeto foram marcados por algumas rupturas pontuais, que inevitavelmente foram refletidas no campo metodológico. Sair do espaço aberto para o interior da sala de teatro permitiu a proposição de jogos e atividades mais intimistas e mais silenciosas, uma vez que um momento de silêncio numa sala de aula é consideravelmente menos ruidoso que o mesmo momento numa rua, praça ou largo. Além da diminuição dos ruídos, também se fez notável a diferença entre a paisagem visual da rua e de um ambiente interno. A rua, por ser muito dispersiva necessitava de atividades dilatadas e correlacionadas aos fluxos e às inúmeras movimentações, enquanto a sala de aula requer atividades que conversem com a estaticidade das paredes de cimento e da luz artificial.

Desse modo, a experimentação pedagógica da segunda fase do projeto encontrou na noite a poética para a sua realização, visto que a noite, no geral, tem familiaridade com ambientes internos, aconchegantes e próprios para dormir. Sendo assim, ações como ir ao chão para descansar tornaram-se parte das aulas, bem como alguns elementos referentes à composição do sonhar. Entender essa composição como metodologia de ensino do Teatro permitiu o encontro de elementos fantásticos com a pedagogia. Nesse sentido, a busca não se dava somente em 
preparar uma aula inspirada em algum sonho, ou fragmento de sonho, mas sim pensar a aula como um sonho, utilizando-nos dos elementos que o compõem, tais quais a sensação de temporalidade difusa, os acontecimentos fantasiosos, a sobreposição e simultaneidade de imagens.

Certamente, o espaço foi um elemento fundamental para a configuração das poéticas do projeto, nas suas primeira e segunda fases. A sua experimentação no primeiro semestre se relacionou mais com uma busca por diferentes locais públicos e abertos, jogando principalmente com as imprevisibilidades e com os diversos cenários encontrados a partir do itinerário traçado. Por conta disso, o espaço e a itinerância tornaram-se partes fundamentais para efetivar a questão da reversibilidade como um conceito que também atravessou esta experiência. A troca de lugar não somente ofereceu uma maior percepção a respeito da relação corpo-espaço-tempo, como também ressaltou a presentificação do corpo no espaço e no tempo. Sendo assim, a reversibilidade tornou-se uma sensação perceptível e relevante para a proposição dessas metodologias. Aqui tocamos em algo muito precioso para pensar o procedimento pedagógico na perspectiva da pedagogia radical, algo próximo ao que Desgranges enuncia como o teatro de arte, definindo-o como aquele que causa, compromete-se com a resistência. Tal resistência implica no exercício de um risco, seja ele perceptual ou de engajamento, ou de entendimento. Ele escreve:

E se a arte teatral deixou de oferecer riscos, é porque deixou de
se colocar em risco, o teatro propõe à plateia aquilo que se espe-
ra dele, que o espectador seja o modelo do cidadão ideal, aquele
que apenas aguarda a cena seguinte. O dito teatro de arte não é
mais um movimento de guerra e, sim, de resistência, tal a indife-
rença a que foi relegado. (DESGRANGES, 2003, p 23).

Assim, para alcançarmos a possibilidade de sonhar com fugas, que nos interessou no processo, seria necessário colocar a aula nesse lugar de risco, de indefinição e imprevisibilidade do próximo passo. Migrar para dentro da sala representou uma 
renúncia a essas condições, mas em contrapartida possibilitou uma compreensão por contraste dos elementos que associamos à noite e aos sonhos. A perda da noção de temporalidade que estar em um ambiente fechado implicava, permitiu um uso mais imaginário do tempo, duração, e a falta de cenários externos inspirou a busca pelas possibilidades de micro-itinerâncias no ambiente interno. Portanto, a principal questão foi encontrar uma maneira de transformar a sala de aula num espaço reversível, trazendo alguns elementos da rua e criando um ambiente mais dinâmico e propositivo, negando a suposta neutralidade que acomoda o espaço para o ensino. Dessa forma, mesmo sem a possibilidade de itinerar entre locais diferentes, houve uma busca por criar espaços dentro de espaços e micro-itinerar entre esses pequenos trajetos.

A relação poética criada entre a sala e a rua foi significativa e enriquecedora e possibilitando clamar pela existência da rua dentro de um ambiente fechado, estranhar elementos da rua, tornando-os inéditos e surreais. Essa combinação misturada à composição do sonhar suscitou a materialização de um espaço inventado, reversível, sonhado e, finalmente, as fugas possíveis.

\section{ONDE O SONHO ACABA E A VIDA (RE)COMEÇA}

Tal qual um sonho, com um final interrompido pelo abrir dos olhos no momento em que se acorda, o projeto foi despertado da mesma forma, com um fim abrupto e inesperado. A exaustão definiu os limites de duração da proposta, atravessamentos para outras direções que marcaram uma chegada antes do que fora planejado. Assim, neste texto, procuramos partilhar questões que consideramos fundamentais para seguir trilhando reflexões sobre o processo pedagógico, na tentativa de expor algumas das assimilações feitas e também do espectro prático e conceitual que envolveu a elaboração e execução do projeto.

Dessa forma, esse projeto que, poderíamos afirmar, começou de dia e terminou de noite, formou o tecido de sua própria 
realidade, tal como um sonho, desses que modulam todo o dia que segue, ao indicar modos de perceber, de acreditar, de sentir e afetar-se nos encontros pedagógicos. Portanto, neste caso, acordar para realidade nada tem a ver com parar de sonhar, mas sim com perceber quais foram os atravessamentos que a experiência onírica nos possibilitou e quão disponíveis estamos para o próximo sonho.

Se a experiência é o que nos acontece, e se o sujeito da experiência é um território de passagem, então a experiência é uma paixão. Não se pode captar a experiência a partir de uma lógica da ação, a partir de uma reflexão do sujeito sobre si mesmo enquanto sujeito agente, a partir de uma teoria das condições de possibilidade da ação, mas a partir de uma lógica da paixão, uma reflexão do sujeito sobre si mesmo enquanto sujeito passional. (LARROSA, 2002, p. 26). 


\section{REFERÊNCIAS}

ALVAREZ, Alfredo. Noite: a vida noturna, a linguagem da noite, o sono e os sonhos. Tradução de Luiz Bernardo Pericás, Bernardo Pericás Neto. São Paulo: Companhia das Letras, 1996.

BERGSON, Henri. O sonho. Revista de Filosofia Trans/form/ação, v. 27, n. 1, p. 93 - 109, 2004.

BONDIA, Jorge Larrosa. Notas sobre a experiência e o saber de experiência. Rev. Bras. Educ. (online), n.19. p. 20-28, 2002.

BONDIA, Jorge Larrosa. Pedagogia Profana: danças, piruetas e mascaradas. Tradução de Alfredo Veiga-Neto. 5. ed.; 2. reimp. Belo Horizonte: Autêntica Editora, 2015.

DESGRANGES, Flávio. A pedagogia do espectador. São Paulo: Editora Huctec, 2003.

HARNEY, Stefano. "Hapticality in the Undercommons or From Operations Management to Black Ops" in Cumma Papers \#9 https://cummastudies.files.wordpress.com/2013/08/cummapapers-9.pdf

HARNEY, Stefano; MOTTEN, Fred. The Undercommons. Fugitive Planning and Black Study. Nova lorque: Minor Compositions, 2013.

MASSUMI, Brian. Parables for the virtual. Movement, affect, sensation. Durnham e Londres: Duke Universitu Press, 2002.

MANCINI, Bianca Scliar C. Anotações sobre Pedagogias Radicais. Revista Nupeart. Florianópolis, v. 16, p. 10 - 21, 2016.

MANNING, Erin. INFLeXions No. 1- How is Research-Creation? (May 2008). Creative Propositions for Thought in Motion. Disponível em http://inflexions.org/n1_manninghtml.html 